\title{
Patient satisfaction after unilateral oncoplastic volume displacement surgery for breast cancer, evaluated with the BREAST-Q ${ }^{\text {TM }}$
}

\author{
Anna Gardfjell ${ }^{1}$, Cecilia Dahlbäck² and Kristina Åhsberg ${ }^{2 *}$
}

\begin{abstract}
Background: Oncoplastic breast-conserving surgery allows larger resections in unfavorable locations, with an improved chance of preserving esthetics. Indications and timing for potential contralateral surgery to obtain symmetry are not clear. The aim of this study was to evaluate patient satisfaction after unilateral oncoplastic volume displacement surgery, to investigate potential risk factors for lower patient satisfaction and to assess patient wish for contralateral surgery.

Method: A cohort of 144 women, consecutively treated for breast cancer with unilateral breast-conserving oncoplastic volume displacement surgery, followed by radiotherapy and with an unoperated contralateral breast, was sent the BREAST-Q ${ }^{\text {TM }}$ breast-conserving therapy (BCT) and a study-specific questionnaire. In all, 120 women (83\%) responded. For these women, the median value for resected specimen weight was $92 \mathrm{~g}$ (range 14-345) and for the estimated percentage of the breast volume excised 15\% (range 3-35\%).

Results: The median patient-reported score for "Satisfaction with breast" (BREAST-Q"M BCT) was 74/100. Factors associated with a score below median value in a simple logistic regression model adjusted for age and BMI were axillary clearance (OR 2.46, 95\% Cl 1.09-5.56), neoadjuvant chemotherapy (OR 3.26, 95\% Cl 1.15-9.24), and low breast density (OR 2.32 95\% Cl 1.02-5.29). Thirteen women (11\%) were interested in contralateral surgery.

Conclusion: Most patients in this study cohort, who had undergone breast-conserving therapy with oncoplastic volume displacement techniques, were satisfied with their breasts without surgery to the contralateral breast. This indicates that contralateral surgery to achieve symmetry only should be performed after individual evaluation and as a delayed procedure.
\end{abstract}

\section{Background}

Breast-conserving therapy $(\mathrm{BCT})$ is the preferred treatment for early-stage breast cancer [1], with equivalent survival $[2,3]$, and esthetic, functional, and psychosocial advantages compared to mastectomy [4,5]. Ideally, the breast should appear normal-looking after BCT. However, studies have shown that up to $30 \%$ of patients have reported unsatisfactory esthetic results that can demand surgical revision [6]. Large excision volume is a wellstudied risk factor for a poor esthetic outcome [7-12],

\footnotetext{
* Correspondence: Kristina.Ahsberg@med.lu.se

2Department of Clinical Sciences Lund, Surgery, Skåne University Hospital,

Lund University, Lund, Sweden

Full list of author information is available at the end of the article
}

the risk increasing if the resection exceeds $15-20 \%$ of the breast volume $[7,8,12]$. In the medial part of the breast, less of the breast volume can be resected with preserved esthetics (5\%) [9]. Beyond possible asymmetry, deformity can also arise due to tissue necrosis, especially in fatty breasts, caused by large dual-plane mobilizations to cover the resected portion [13]. Tumor location in the medial, inferior, or central parts of the breast is also related to lower satisfaction after BCT $[10,11,14,15]$. In addition, postoperative radiotherapy (PRT) can accentuate a suboptimal esthetic result by substantial and unpredictable shrinkage [16-18]. Other observed risk factors for lower patient satisfaction after BCT have been high body mass index (BMI) [12, 14], axillary

(c) The Author(s). 2019 Open Access This article is distributed under the terms of the Creative Commons Attribution 4.0 International License (http://creativecommons.org/licenses/by/4.0/), which permits unrestricted use, distribution, and reproduction in any medium, provided you give appropriate credit to the original author(s) and the source, provide a link to the Creative Commons license, and indicate if changes were made. The Creative Commons Public Domain Dedication waiver (http://creativecommons.org/publicdomain/zero/1.0/) applies to the data made available in this article, unless otherwise stated. 
clearance [12], postoperative complications [11, 12, 14], reoperative procedures $[10,12,14]$, adjuvant chemotherapy [15], large scars after resection [10], and how the patient perceived the preoperative information and possibility to participate in decision-making regarding surgical technique [19]. The impact of these factors has varied between studies.

Where $\mathrm{BCT}$ is contraindicated due to poor expected esthetic outcome, the use of oncoplastic breastconserving surgery (OPS) has rapidly increased during the last decade [20]. OPS can allow a wider excision of the tumor, thereby ensuring safer margins and widening the possibility of breast-conserving surgery. For some women, this can spare them a mastectomy, without compromising local control. In addition, a so called oncoplastic mammoplasty (OPS with techniques similar to a reduction mammoplasty) can be performed if the patient has large breasts, and a reduction of the breast volume is beneficial to simplify PRT. After operation with a volume displacement technique, a slight asymmetry can be expected regarding size and ptosis of the breast, although the shape of the breast and centralization of the nipple is preserved [13]. As symmetry is presented to be of great importance for patient satisfaction $[14,17,21]$, many breast centers also operate on the contralateral breast in the primary setting to ensure postoperative symmetry. However, there are no firm guidelines specifying in which cases contralateral surgery should be performed, and a recent interview study showed that patients accept a slight asymmetry due to concerns regarding risks with surgery and the will to preserve the untouched contralateral, healthy breast [22].

Patient-reported outcome measures (PROMs), are essential instruments to gain information regarding the patient's experience and health-related quality of life (HRQoL). The BREAST- $\mathrm{Q}^{\text {tw }}$ questionnaires are currently the only validated, disease-specific questionnaires, designed to evaluate different aspects of HR-QoL and patient satisfaction after breast cancer surgery [23]. The BREAST$\mathrm{Q}^{\mathrm{m}}$ modules are used globally, and have been used in studies to compare various surgical techniques for breast cancer [24]. To date, there are five studies that have used the BREAST-Q ${ }^{\mathrm{Tm}}$ BCT to evaluate results after BCT [2529]. Although some of the studies have included patients operated with various oncoplastic techniques, no study has yet evaluated a cohort of patients consistently operated with volume displacement OPS with the BREAST$\mathrm{Q}^{\mathrm{Tm}} \mathrm{BCT}$.

\section{Method}

\section{Study aim}

The aim of this study was to evaluate postoperative patient satisfaction, using the BREAST-Q ${ }^{\mathrm{Tm}} \mathrm{BCT}$, after unilateral volume displacement OPS and radiotherapy, without surgery to the contralateral breast. Secondary aims were to find potential determinants for poor patient satisfaction and to assess patient wish to undergo contralateral surgery.

\section{Participant recruitment}

Women consecutively operated with unilateral oncoplastic breast-conserving surgery for malignant breast disease between 1 March 2013 and 31 December 2016 at the Skåne University Hospital in Lund were identified through a systematical search in the local surgery planning program. All patients coded with Nordic MedicoStatistical Committee (NOMESCO) classification of surgical procedures (NCSP [30]), operational code HAB40 (wedge excision of the mammary gland), were located $(n=673)$. Of these, 210 patients had the additional code of ZZR70 (flap of mammary gland tissue) and represented the number of women recorded as operated with volume displacement oncoplastic surgery (Fig. 1).

A review of medical charts was performed prior to study inclusion to ascertain that PRT had been completed at least 1 year prior to the study and that no surgery to the contralateral breast had been performed (Fig. 1). In total, 64 women were excluded from the study. Eight women had been incorrectly coded with ZZR70. Five women had a benign diagnosis. Twentyseven women had been reoperated with a mastectomy: twenty-five due to positive surgical margins, one due to a local recurrence, and one had undergone prophylactic bilateral mastectomy due to a BRCA-1 mutation. Three women had not received PRT: one due to a preexisting heart condition, one declined treatment, and for one patient the histopathological analysis showed malignant phyllodes tumor, for which PRT is not indicated. Seventeen women had undergone bilateral surgery: eight women had been operated for a previous cancer, three women had bilateral cancers, and six women were operated on the contralateral breast to achieve symmetry. Four women had died prior to the study: three from metastatic breast cancer and one from a stroke. The remaining 146 women were sent the questionnaires. Two patients declined participation and were excluded, and all collected data from their medical charts were deleted.

\section{Data collection}

Data were collected regarding OPS technique, tumor size and location, postoperative complications, reoperations due to inadequate margins, pathological anatomical diagnosis, volume and weight of the specimen, tobacco use, patient age and BMI at time of surgery, and neoadjuvant and adjuvant treatment. Postoperative complications were defined by the 


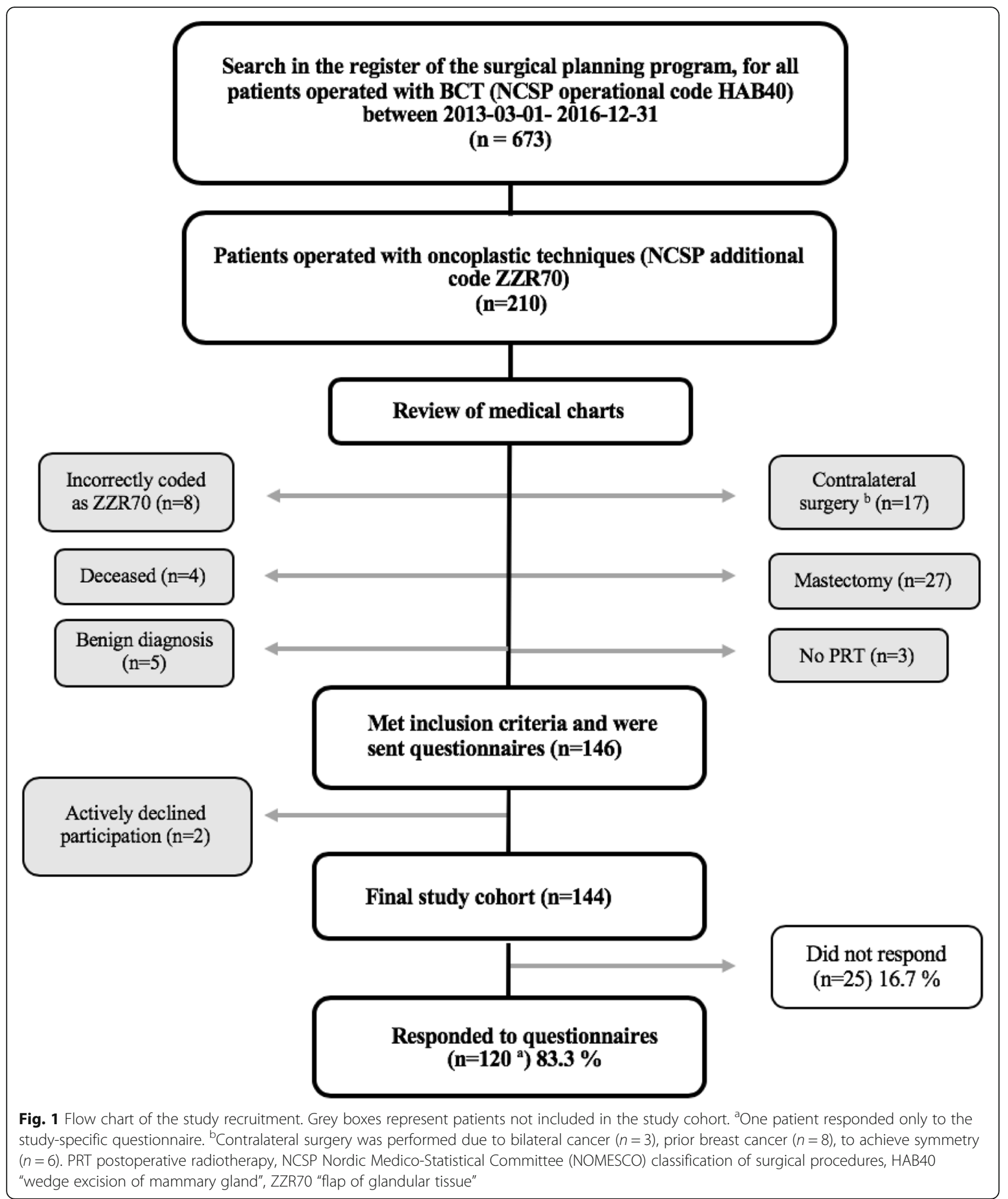

Clavien-Dindo classification system [31]. Only complications that concerned the breast were included. Mammograms were assessed to estimate preoperative breast tissue composition and calculate breast volume.
The algorithm for volume calculation uses measurements of width, $w$, and height, $h$, from the craniocaudal projection of the mammogram together with the measurement of compression, $c$ (thickness of the 
breast when compressed during mammography), defining the breast as a half-elliptical cylinder; volume ( $\left.\mathrm{cm}^{3}\right)=\pi / 4 \times w h c(\mathrm{~cm})$. The method has been validated by Kalbhen et al. [32] and Kayar et al. [33]. Preoperative composition of breast tissue was evaluated by a senior consultant of radiology, who categorized the images into groups $\mathrm{A}-\mathrm{D}$, in accordance with the American College of Radiology's Breast Imaging Reporting and Data System (BI-RADS ${ }^{\circ}$ ) 5th edition [34]. Specimens were weighed to the closest gram at the surgical theater directly after excision, before formalin fixation. Fresh specimen weight was used as a surrogate for volume in the current study, assuming that breast tissue weighs $1 \mathrm{~g} / \mathrm{cm}^{3}$, which has been implemented in previous studies $[8,12]$. Estimated percentage of breast volume excised (EPBVE) was calculated by dividing specimen weight with preoperative breast volume. Follow-up time was defined as the number of months between the date of operation and the date when the questionnaires were sent out to the individual.

\section{Surgery and systemic treatment}

OPS is used at our unit if the tumor is located caudally, medially, or centrally, or where tumor/breast volume ratio is $>20 \%$. It is also an option at reoperation after an initial wide local excision (WLE) with positive margins. Most of the performed techniques are those presented by Clough et al. in Ann Surg Oncology 2010 [13], and most cases fall under the volume displacement category of OPS. At this kind of operation, routinely, only the cancer-burdened breast is operated in the primary setting unless a reduction mammoplasty is favorable to simplify PRT.

Preoperatively, radiological tumor location and extent was assessed with full-field digital mammography and ultrasonography. Before neoadjuvant treatment, a clip was placed in the tumor. At the preoperative multidisciplinary conference, a recommendation is made for mastectomy or breast-conserving surgery for the individual patient, but the definitive choice of breastconserving technique and use of oncoplastic procedures is made by the surgeon who sees the patient. For nonpalpable lesions, a wire was placed in the tumor or area of calcifications before surgery. Operations were performed by seven breast surgeons with training in OPS. Two consultants performed a majority of the operations, $43.1 \%(n=62)$ and $25.7 \%(n=37)$, respectively, with the remaining five surgeons performing $31.2 \%(n=45)$. Patient satisfaction in relation to the surgeon was not analyzed. Sentinel node biopsy with dual technique was routinely used to assess axillary node status. Axillary clearance was performed in patients with positive lymph nodes, if not included in the SENOMIC trial [35] or randomized to no further surgery in the SENOMAC trial [36]. If the placement of the breast incision is permitted, the same incision was used for axillary surgery. Otherwise, a separate incision was made. An intraoperative Xray of the resected specimen was performed to ensure a radiological margin of minimum $10 \mathrm{~mm}$. If radiological margins were inadequate, additional tissue was excised during the same operation. Pathological evaluation of the margins by frozen section is not used routinely at our unit. Patients were treated neoadjuvantly and adjuvantly in accordance with the Swedish national guidelines for breast cancer treatment [37], involving radio-, endocrine, chemo-, and anti-HER2 therapy, depending on tumor stage and histopathological profile.

\section{Questionnaires}

The BREAST-Q ${ }^{\mathrm{mi}}$ BCT is a standardized, validated disease-specific PROM developed to evaluate patient satisfaction and HR-QoL after BCT. It is divided into nine domains for evaluation of satisfaction with breasts; adverse effects of radiation; psychosocial, physical and sexual well-being; perception of information prior to surgery; and interactions with different categories of medical staff. [23]. Patients were provided with a linguistically validated Swedish translation of the questionnaire [26].

Some questions of special interest to the current study were not included in the BREAST- $\mathrm{Q}^{\mathrm{m}} \mathrm{BCT}$. Therefore, a study-specific questionnaire was constructed which included questions assessing satisfaction regarding different aspects of the operated breast, satisfaction with preoperative information, perception of ability to participate in the preoperative decision-making process, and wish for corrective surgery of either breast. Inspiration was taken from a previous study from SUS Malmö Surgical Center [26] that evaluated patient satisfaction after conventional breast-conserving surgery (BCS).

\section{Statistical methods and data analysis}

The BREAST-Q ${ }^{\mathrm{m}}$ BCT was analyzed as complete domains with a manual scoring table provided by the developers (http://qportfolio.org/breast-q/breast-cancer/). Raw data were thus converted to a " $Q$-score" ranging from 0 to 100 . A high score is meant to correspond to a higher HR-QoL. Patients who answered less than 50\% of the questions on a scale were excluded from that specific scale. Missing values up to $50 \%$ of the scale were replaced by calculating the mean value of the answered questions and using this as a surrogate for the missing value(s), thus completing all items of the scale.

Descriptive statistics for parametric variables were expressed as median, interquartile range (IQR), and range due to a skewed distribution in the continuous 
variables. Descriptive statistics for non-parametric variables were presented as frequencies and percentages. Fisher's exact test was used to find differences between subgroups (dichotomous variables). Spearman's rho was used to analyze correlations between different domains of the BREAST-Q ${ }^{\mathrm{m}}$ (continuous Q-scores) and between the BREAST-Q ${ }^{\mathrm{m}}$ (continuous Q-scores) and the studyspecific questionnaire (4-point scales). The associations between $Q$-scores and potential determinants for lower satisfaction were analyzed by dichotomizing Q-scores with a cutoff at the median value. Logistic regression analysis was used to investigate the associations. Odds ratios (OR) with $95 \%$ confidence intervals $(\mathrm{CI})$ were obtained. Associations with potential risk factors for lower satisfaction after unilateral volume displacement OPS were first analyzed in a simple logistic regression model, and thereafter in a model adjusted for BMI and age, and finally in a multiple logistic regression model including factors in which a statistically significant association had been observed in the simple logistic regression analysis.

Statistical analyses were performed using $\mathrm{IBM}^{\circ}$ SPSS Statistics for Macintosh, Version 24.0. IBM Corp., Armonk, NY.

\section{Results}

\section{Demographics of responding patients}

Response rate was $83.3 \%$, as 120 of the included 144 women responded (Fig. 1). One patient answered only the study-specific questionnaire, and the remaining 119 answered both questionnaires. Patient, tumor, and treatment characteristics for the total cohort and for responders and non-responders, respectively, are shown in Table 1. For responding patients, median age at operation was 61 (33-80) years and median BMI 25.2 (16.0-42.0) kg/m², median follow-up time $28(15-54)$ months, median radiological and histological tumor extents (including malignant microcalcifications and DCIS) were $20(5-60) \mathrm{mm}$ and $22(6-90) \mathrm{mm}$, respectively, specimen weight $92(14-345)$ grams and EPBVE 15\% (3-35\%).

\section{Surgical and treatment specifications of responding patients}

The most frequent technique, the Raquet oncoplasty, was used in $54.2 \%$ of the patients $(n=65)$. Axillary clearance was performed in $25.0 \%(n=30)$. Two women were reoperated with OPS after an initial WLE with insufficient margins. Five women $(4.2 \%)$ were re-excised after the initial OPS with insufficient margins, with a final result of BCT. Neoadjuvant chemotherapy was administered to $17.5 \%(n=21)$. Adjuvant chemo- and endocrine therapy were given to $26.7 \%(n=32)$ and $74.2 \%(n=89)$, respectively. All women received PRT.

\section{Complications of responding patients}

Six women $(5.0 \%)$ had complications from the breast area (Table 1): three grade 1 complications (one hematoma and two minor skin necroses), one grade 2 complication (infection treated with antibiotics), and two grade $3 \mathrm{~b}$ complications (reoperation due to postoperative bleeding). Due to infection, adjuvant radiotherapy was delayed by three weeks in one case.

\section{Patient satisfaction}

The median $Q$-scores of the BREAST-Q ${ }^{\mathrm{mm}}$ BCT domains were for "Satisfaction with breast" 74/100 (IQR 59-85), "Psychosocial well-being" 87/100 (IQR 57-100), and "Sexual well-being" 60/100 (IQR 40-69). Of the women, 97.5-100\% answered more than half of the BREAST- ${ }^{\mathrm{m}}$ BCT domains, with an exception for "Sexual QoL", in which the completion percentage was $64.7 \%$ (Table 2).

In the study-specific questionnaire, $88.3 \%(n=106)$ of the women were satisfied or very satisfied with the appearance of the operated breast, $86.7 \%(n=104)$ with the size of the operated breast, $88.3 \%(n=106)$ with the shape of the operated breast, $78.3 \%(n=94)$ with the symmetry between the operated and untouched breast, $90.8 \%(n=109)$ with the nipple-areolar complex (NAC) positioning, $85.8 \%(n=103)$ with the appearance of the NAC, $83.3 \%(n=100)$ with the scar, and $79.2 \%(n=95)$ with skin sensitivity (Table 3 ).

Determinants for patient satisfaction in the BREAST$\mathrm{Q}^{\mathrm{mi}} \mathrm{BCT}$ domain "Satisfaction with breast" below median value $(Q$-score $<74)$ in the crude logistic regression analysis were found to be specimen weight $>100 \mathrm{~g}$, axillary clearance, neoadjuvant therapy, and breasts with low density (BI-RADS $\left.{ }^{\circ} \mathrm{A}-\mathrm{B}\right)$. The factors that remained significant when adjusted for age and BMI were axillary clearance (OR 2.46, 95\% CI 1.09-5.56), neoadjuvant chemotherapy (OR 3.26, 95\% CI 1.15-9.24), and low breast density (OR 2.32, 95\% CI 1.02-5.29) (Table 4). No independent risk factors were found in the multiple logistic regression model (Table 5).

\section{Wish for contralateral surgery}

Thirteen of the responding women (11\%) expressed interest for a contralateral operation. Median time since surgery was 30 months for these women (range 17-53), and in most cases, they had previously not expressed a wish $(n=5)$ for contralateral surgery at clinical followup. In some cases $(n=4)$, the patients had too high BMI to be subjected to a contralateral reduction mammaplasty according to the National Guidelines. In two cases, there was an indication for contralateral surgery according to both the surgeon and patient; however, a decision to further await contralateral surgery was made, since the effects of postoperative radiotherapy and/or endocrine therapy were expected to further affect the 
Table 1 Patient, tumor, and therapy characteristics. All values are presented as median (range) or percentage (count) of subgroup

\begin{tabular}{|c|c|c|c|}
\hline & Total cohort $(n=144)$ & Responders $(n=120)$ & Non-responders $(n=24)$ \\
\hline Age (years) & $60(32-80)$ & $61(33-80)$ & $52(32-79)$ \\
\hline BMI $\left(\mathrm{kg} / \mathrm{m}^{2}\right)$ & $25.1(16.0-42.0)^{d}$ & $25.2(16.0-42.0)$ & $24.2(19.7-34.6)$ \\
\hline Smoker & $14.0 \%(n=20)$ & $11.8 \%(n=14)$ & $25.0 \%(n=6)$ \\
\hline Radiological tumor extent (mm) & $20(5-60)$ & $20(5-60)$ & $25(6-60)$ \\
\hline Histological tumor extent (mm) & $23(6-90)$ & $22(6-90)$ & $25(10-51)$ \\
\hline Specimen weight (g) & $86(14-345)^{\mathrm{e}}$ & $92(14-345)$ & $62(33-161)$ \\
\hline Breast volume $\left(\mathrm{cm}^{3}\right)^{\mathrm{a}}$ & $644(110-2033)^{f}$ & $644(110-2033)$ & 637 (200-1395) \\
\hline EPBVE $(\%)^{b}$ & $14(3-35)^{9}$ & $15(3-35)$ & $13(7-28)$ \\
\hline \multicolumn{4}{|l|}{ Oncoplastic method } \\
\hline Raquet & $49.3 \%(n=71)$ & $54.2 \%(n=65)$ & $25.0 \%(n=6)$ \\
\hline Round block & $21.5 \%(n=31)$ & $20.0 \%(n=24)$ & $29.2 \%(n=7)$ \\
\hline V-mammoplasty & $13.2 \%(n=19)$ & $10.8 \%(n=13)$ & $25.0 \%(n=6)$ \\
\hline Inverted-T & $7.6 \%(n=11)$ & $7.5 \%(n=9)$ & $8.3 \%(n=2)$ \\
\hline J-mammoplasty & $6.9 \%(n=10)$ & $6.7 \%(n=8)$ & $8.3 \%(n=2)$ \\
\hline Other & $1.4 \%(n=2)$ & $0.8 \%(n=1)$ & $4.2 \%(n=1)$ \\
\hline Axillary clearance & $27.8 \%(n=40)$ & $30.0 \%(n=36)$ & $16.7 \%(n=4)$ \\
\hline Re-excision & $4.9 \%(n=7)$ & $4.2 \%(n=5)$ & $8.3 \%(n=2)$ \\
\hline \multicolumn{4}{|c|}{ Postoperative complications of the breast ${ }^{c}$} \\
\hline Grade 1 & $2.1 \%(n=3)$ & $2.5 \%(n=3)$ & 0 \\
\hline Grade 2 & $2.1 \%(n=3)$ & $0.8 \%(n=1)$ & $8.3 \%(n=2)$ \\
\hline Grade 3 & $1.4 \%(n=2)$ & $1.7 \%(n=2)$ & 0 \\
\hline Neoadjuvant chemotherapy & $17.4 \%(n=25)$ & $17.5 \%(n=21)$ & $16.7 \%(n=4)$ \\
\hline Adjuvant chemotherapy & $25.0 \%(n=36)$ & $26.7 \%(n=32)$ & $16.7 \%(n=4)$ \\
\hline Adjuvant endocrine therapy & $72.2 \%(n=104)$ & $74.2 \%(n=89)$ & $62.5 \%(n=15)$ \\
\hline Postoperative radiotherapy & $100 \%(n=144)$ & $100 \%(n=120)$ & $100 \%(n=24)$ \\
\hline \multicolumn{4}{|l|}{ Breast density } \\
\hline High (BI-RADS $\left.{ }^{\oplus} \mathrm{C}-\mathrm{D}\right)$ & $30.6 \%(n=55)$ & $54.2 \%(n=13)$ & $35.0 \%(n=42)$ \\
\hline Low (BI-RADS $\left.{ }^{\oplus} A-B\right)$ & $62.5 \%(n=89)$ & $45.8 \%(n=11)$ & $65.0 \%(n=78)$ \\
\hline Follow-up time (months) & $27(15-54)$ & $28(15-54)$ & $24(15-54)$ \\
\hline
\end{tabular}

$B M I$ body mass index, EPBVE estimated percentage of breast volume excised, BI-RADS ${ }^{\circledR}$ Breast Imaging Reporting and Data System

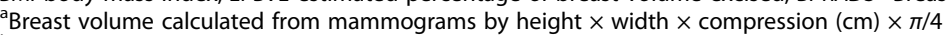

bEPBVE calculated by dividing specimen weight with breast volume

'Complications defined by the Clavien-Dindo classification [31]

dOne missing value in the "non-responder" group

eEight missing values, out of which seven were in the "responder" group and one in the "non-responder"

"Two missing values in the "responder" group

9Ten missing values, out of which nine were in the "responder" group and one in the "non-responder" group

breast. One patient had the clinical follow-up at the oncological department and had therefore not been in contact with the surgical department. One patient was on the waiting list for a contralateral procedure.

The women who wished to have contralateral surgery for symmetry reported a higher frequency of dissatisfaction regarding the size and shape of the operated breast and with postoperative symmetry between the breasts (Table 6).

\section{Correlation between "Satisfaction with breasts" and other BREAST-Q ${ }^{\text {TM }}$ BCT domains}

The domain "Satisfaction with breasts" had positive correlation coefficients with all other BREAST-Q ${ }^{\mathrm{m}}$ BCT domains. "Sexual well-being" was found to have the highest correlation (Spearman's rho $=0.584$, moderate) and "Psychosocial well-being" the second highest correlation (rho $=0.562$, moderate). Correlations are presented in Table 7 along with $p$ values.

\section{Discussion}

During the last decade, the use of oncoplastic surgery has increased rapidly. Intentions have been to widen the implementation of $\mathrm{BCT}$, thus avoiding mastectomy or increasing patient satisfaction in challenging cases [13, 20]. The BREAST-Q ${ }^{\text {max }}$ questionnaires are currently the only available validated and disease-specific PROMs for 
Table 2 Q-scores for BREAST-Q Q ${ }^{\text {TM }}$ BCT Domains

\begin{tabular}{|c|c|c|c|c|c|}
\hline Domain & $n$ & Median & IQR & Range & Mean (SD) \\
\hline 1. Satisfaction with breasts & 119 & 74 & $59-85$ & $12-100$ & $72(20)$ \\
\hline 2. Adverse effects of radiation & 118 & 100 & $89-100$ & $49-100$ & $94(11)$ \\
\hline 3. Psychosocial well-being & 119 & 87 & $57-100$ & $14-100$ & $78(23)$ \\
\hline 4. Sexual well-being & 77 & 60 & $40-69$ & $0-100$ & $55(21)$ \\
\hline 5. Physical well-being & 119 & 78 & $69-92$ & $21-100$ & $78(18)$ \\
\hline 6. Satisfaction with information from breast surgeon & 119 & 75 & $58-100$ & $37-100$ & $76(19)$ \\
\hline 7. Satisfaction with breast surgeon & 118 & 100 & $92-100$ & $23-100$ & $92(14)$ \\
\hline 8. Satisfaction with medical team & 118 & 100 & $100-100$ & $31-100$ & $96(12)$ \\
\hline 9. Satisfaction with office staff & 116 & 100 & $100-100$ & $44-100$ & $97(9)$ \\
\hline
\end{tabular}

Number of responders and descriptive statistics of Q-scores from domains of the BREAST- $Q^{\mathrm{TM}} B C T$

$I Q R$ interquartile range, $S D$ standard deviation, $n$ number of responders (maximum 119 patients since one of the 120 responding patients only answered the study-specific questionnaire)

Table 3 Descriptive statistics of answers to the study-specific questionnaire

\begin{tabular}{|c|c|c|c|c|c|}
\hline \multicolumn{6}{|l|}{ Expectations, information, participation in decision-making } \\
\hline & Not at all & Partly & $\begin{array}{l}\text { Almost } \\
\text { entirely }\end{array}$ & Entirely & Missing \\
\hline Has the operation met your expectations regarding the cosmetic outcome? & $1(0.8 \%)$ & $8(6.7 \%)$ & $30(25.0 \%)$ & $79(65.8 \%)$ & $\begin{array}{l}2 \\
(1.7 \%)\end{array}$ \\
\hline Did you receive enough information about the expected cosmetic outcome? & $6(5.0 \%)$ & $14(11.7 \%)$ & $24(20.0 \%)$ & $74(61.7 \%)$ & $\begin{array}{l}2 \\
(1.7 \%)\end{array}$ \\
\hline $\begin{array}{l}\text { Did you perceive an opportunity to participate in the decision making } \\
\text { process? }\end{array}$ & $20(16.7 \%)$ & $16(13.3 \%)$ & $20(16.7 \%)$ & $62(51.7 \%)$ & $\begin{array}{l}2 \\
(1.7 \%)\end{array}$ \\
\hline \multicolumn{6}{|l|}{ Satisfaction with different aspects of the operated breast } \\
\hline & Dissatisfied & $\begin{array}{l}\text { Not entirely } \\
\text { satisfied }\end{array}$ & Satisfied & $\begin{array}{l}\text { Very } \\
\text { satisfied }\end{array}$ & Missing \\
\hline Appearance of the operated breast & $4(3.3 \%)$ & $10(8.3 \%)$ & $42(35.0 \%)$ & $64(53.3 \%)$ & 0 \\
\hline Size of the operated breast & $4(3.3 \%)$ & $11(9.2 \%)$ & $46(38.3 \%)$ & $58(48.3 \%)$ & $\begin{array}{l}1 \\
(0.8 \%)\end{array}$ \\
\hline Shape of the operated breast & $3(2.5 \%)$ & $10(8.3 \%)$ & $47(39.2 \%)$ & $59(49.2 \%)$ & $\begin{array}{l}1 \\
(0.8 \%)\end{array}$ \\
\hline NAC positioning & $2(1.7 \%)$ & $8(6.7 \%)$ & $44(36.7 \%)$ & $65(54.2 \%)$ & $\begin{array}{l}1 \\
(0.8 \%)\end{array}$ \\
\hline NAC appearance & $2(1.7 \%)$ & $12(10.0 \%)$ & $46(38.3 \%)$ & $57(47.5 \%)$ & $\begin{array}{l}3 \\
(2.5 \%)\end{array}$ \\
\hline Symmetry & $6(5.0 \%)$ & $19(15.8 \%)$ & $50(41.7 \%)$ & $44(36.7 \%)$ & $\begin{array}{l}1 \\
(0.8 \%)\end{array}$ \\
\hline Appearance of scar & $4(3.3 \%)$ & $13(10.8 \%)$ & 47 (39.2\%) & $53(44.2 \%)$ & $\begin{array}{l}3 \\
(2.5 \%)\end{array}$ \\
\hline Skin sensitivity & $5(4.2 \%)$ & $18(15.0 \%)$ & $56(46.7 \%)$ & $39(32.5 \%)$ & $\begin{array}{l}2 \\
(1.7 \%)\end{array}$ \\
\hline \multicolumn{6}{|l|}{ Wish regarding additional/corrective/other surgery } \\
\hline & \multicolumn{2}{|l|}{ No } & Yes & \multicolumn{2}{|l|}{ Missing } \\
\hline Would you rather have removed the entire breast? & \multicolumn{2}{|l|}{$114(95.0 \%)$} & $3(2.5 \%)$ & \multicolumn{2}{|l|}{$3(2.5 \%)$} \\
\hline Would you like to have corrective surgery of the operated breast? & \multicolumn{2}{|l|}{$109(90.8 \%)$} & $8(6.7 \%)$ & \multicolumn{2}{|l|}{$3(2.5 \%)$} \\
\hline Would you like to have a procedure of the contralateral breast for symmetry? & \multicolumn{2}{|l|}{$101(84.2 \%)$} & $13(10.8 \%)$ & \multicolumn{2}{|l|}{$6(5.0 \%)$} \\
\hline
\end{tabular}


Table 4 Logistic regression model of potential risk factors for lower patient satisfaction

\begin{tabular}{|c|c|c|c|c|}
\hline Factor & Q-score $\geq 74$ & Q-score $<74$ & OR $(95 \% \mathrm{Cl})^{\mathrm{a}}$ & $\mathrm{OR}(95 \% \mathrm{Cl})^{\mathrm{b}}$ \\
\hline \multicolumn{5}{|l|}{$\overline{B M I}\left(\mathrm{~kg} / \mathrm{m}^{2}\right)$} \\
\hline$<25$ & $31(54.4 \%)$ & $26(45.6 \%)$ & 1 & 1 \\
\hline$\geq 25$ to $<30$ & $21(47.7 \%)$ & $23(52.3 \%)$ & $1.31(0.59-2.87)$ & $1.28(0.58-2.84)$ \\
\hline$\geq 30$ & $9(50.0 \%)$ & $9(50.0 \%)$ & $1.19(0.41-3.44)$ & $1.18(0.40-3.46)$ \\
\hline \multicolumn{5}{|l|}{ Age (years) } \\
\hline$<50$ & $18(56.3 \%)$ & $14(43.8 \%)$ & 1 & 1 \\
\hline $50-65$ & $21(46.7 .7 \%)$ & $24(53.3 \%)$ & $1.47(0.59-3.66)$ & $1.44(0.58-3.60)$ \\
\hline$>65$ & $22(52.4 \%)$ & $20(47.6 \%)$ & $1.17(0.46-2.95)$ & $1.14(0.45-2.91)$ \\
\hline \multicolumn{5}{|c|}{ BI-RADS ${ }^{\circledR}$ classification of breast density } \\
\hline High density(C-D) & $27(64.3 \%)$ & $15(35.7 \%)$ & 1 & 1 \\
\hline Low density (A-B) & $34(44.2 \%)$ & $43(55.8 \%)$ & $2.28(1.05-4.94)$ & $2.32(1.02-5.29)$ \\
\hline \multicolumn{5}{|c|}{ Smoker } \\
\hline No & $53(52.5 \%)$ & $48(47.5 \%)$ & 1 & 1 \\
\hline Yes & $4(28.6 \%)$ & $10(71.4 \%)$ & $2.76(0.81-9.38)$ & $2.59(0.74-9.12)$ \\
\hline \multicolumn{5}{|c|}{$\operatorname{EPBVE}(\%)^{c}$} \\
\hline$<15$ & $31(50.8 \%)$ & $30(49.2 \%)$ & 1 & 1 \\
\hline$\geq 15$ & $25(51.0 \%)$ & $24(49.0 \%)$ & $0.99(0.47-2.11)$ & $1.00(0.45-2.21)$ \\
\hline \multicolumn{5}{|c|}{ Specimen weight (grams) } \\
\hline$<100$ & $40(58.8 \%)$ & $28(41.2 \%)$ & 1 & 1 \\
\hline$\geq 100$ & $17(38.6 \%)$ & $27(61.4 \%)$ & $2.27(1.05-4.93)$ & $2.23(0.99-5.06)$ \\
\hline \multicolumn{5}{|c|}{ Axillary clearance } \\
\hline No & $48(57.8 \%)$ & 35 (42.2\%) & 1 & 1 \\
\hline Yes & $13(36.1 \%)$ & $23(63.9 \%)$ & $2.43(1.08-5.44)$ & $2.46(1.09-5.56)$ \\
\hline \multicolumn{5}{|c|}{ Neoadjuvant chemotherapy } \\
\hline No & $55(56.1 \%)$ & $43(43.9 \%)$ & 1 & 1 \\
\hline Yes & $6(28.6 \%)$ & $15(71.4 \%)$ & $3.20(1.15-8.93)$ & $3.26(1.15-9.24)$ \\
\hline \multicolumn{5}{|c|}{ Adjuvant chemotherapy } \\
\hline No & 47 (54.0\%) & $40(46.0 \%)$ & 1 & 1 \\
\hline Yes & $14(43.8 \%)$ & $18(56.3 \%)$ & $1.51(0.67-3.42)$ & $1.54(0.67-3.52)$ \\
\hline \multicolumn{5}{|c|}{ Adjuvant endocrine therapy } \\
\hline No & $15(48.4 \%)$ & $16(51.6 \%)$ & 1 & 1 \\
\hline Yes & $46(52.3 \%)$ & $42(47.7 \%)$ & $0.86(0.38-1.94)$ & $0.82(0.35-1.89)$ \\
\hline
\end{tabular}

$B I-R A D S^{\oplus}$ Breast Imaging Reporting and Data System, EPBVE estimated percentage of breast volume excised, $B M I$ body mass index

${ }^{\text {a }}$ Simple logistic regression model. OR > 1 equals higher likelihood for lower satisfaction (Q-score under median value in the BREAST-Q ${ }^{\text {TM }}$ BCT domain "Satisfaction with breast"). Presented as fitted model with $95 \% \mathrm{Cl}$ in brackets. Text in italics highlights statistically significant values

${ }^{\mathrm{b}}$ Multiple logistic regression model, factor adjusted for age and BMI

'Divided at median value of responding patients

subjective auto-evaluation after breast cancer surgery. To our knowledge, there are to date five published studies that have used BREAST- $\mathrm{Q}^{\mathrm{Tm}} \mathrm{BCT}$, two of them evaluating OPS $[23,27]$ and the other three evaluating nonspecified BCS [24-26]. Out of these studies, Dahlbäck et al. [24] and O'Connell et al. [25] are considered appropriate for comparison since they presented median values and had the highest response rates (Table 8).

Even though tumor extent and resected specimen weight were larger in the current study, the median Qscore of the BREAST-Q" domain "Satisfaction with breasts" was higher than the $Q$-scores presented by 
Table 5 Multiple logistic regression model including factors showing a statistically significant association in the simple logistic regression model

\begin{tabular}{|c|c|c|c|c|}
\hline Factor & Q-score $\geq 74$ & Q-score $<74$ & OR $(95 \% C l)^{a}$ & OR $(95 \% \mathrm{Cl})^{\mathrm{b}}$ \\
\hline \multicolumn{5}{|l|}{ BMI $\left(\mathrm{kg} / \mathrm{m}^{2}\right)$} \\
\hline$<25$ & $31(54.4 \%)$ & $26(45.6 \%)$ & 1 & 1 \\
\hline$\geq 25$ to $<30$ & $21(47.7 \%)$ & $23(52.3 \%)$ & $1.28(0.58-2.84)$ & $1.21(0.50-2.90)$ \\
\hline$\geq 30$ & $9(50.0 \%)$ & $9(50.0 \%)$ & $1.18(0.40-3.46)$ & $1.08(0.32-3.68)$ \\
\hline \multicolumn{5}{|l|}{ Age (years) } \\
\hline$<50$ & $18(56.3 \%)$ & $14(43.8 \%)$ & 1 & 1 \\
\hline $50-65$ & $21(46.7 .7 \%)$ & $24(53.3 \%)$ & $1.44(0.58-3.60)$ & $1.06(0.39-2.93)$ \\
\hline$>65$ & $22(52.4 \%)$ & $20(47.6 \%)$ & $1.14(0.45-2.91)$ & $0.81(0.28-2.33)$ \\
\hline \multicolumn{5}{|c|}{ BI-RADS ${ }^{\oplus}$ classification of breast density } \\
\hline High density (C-D) & $27(64.3 \%)$ & $15(35.7 \%)$ & 1 & 1 \\
\hline Low density (A-B) & $34(44.2 \%)$ & $43(55.8 \%)$ & $2.32(1.02-5.29)$ & $2.00(0.79-5.06)$ \\
\hline \multicolumn{5}{|c|}{ Axillary clearance } \\
\hline No & $48(57.8 \%)$ & $35(42.2 \%)$ & 1 & 1 \\
\hline Yes & $13(36.1 \%)$ & $23(63.9 \%)$ & $2.46(1.09-5.56)$ & $1.57(0.52-4.72)$ \\
\hline \multicolumn{5}{|c|}{ Neoadjuvant chemotherapy } \\
\hline No & 55 (56.1\%) & $43(43.9 \%)$ & 1 & 1 \\
\hline Yes & $6(28.6 \%)$ & $15(71.4 \%)$ & $3.26(1.15-9.24)$ & $3.02(0.70-13.12)$ \\
\hline \multicolumn{5}{|c|}{ Specimen weight (grams) } \\
\hline$\leq 100$ & $40(58.8 \%)$ & $28(41.2 \%)$ & 1 & 1 \\
\hline$>100$ & $17(38.6 \%)$ & $27(61.4 \%)$ & $2.23(0.99-5.06)$ & $1.45(0.59-3.54)$ \\
\hline
\end{tabular}

$B I-R A D S^{\oplus}$ Breast Imaging Reporting and Data System, $B M I$ body mass index

${ }^{\mathrm{a}}$ Model where the factor is adjusted for age and BMI. OR $>1$ equals higher likelihood for lower satisfaction (Q-score under median value in the BREAST-Q ${ }^{\mathrm{TM}}$ BCT domain 'Satisfaction with breast'). Presented as fitted model with $95 \% \mathrm{Cl}$ in brackets, adjusted for BMI and age. Text in italics highlights statistically significant values

${ }^{\mathrm{b}}$ Multiple logistic regression model where all factors shown were adjusted for each other

Table 6 Satisfaction with different aspects of the operated breast for patients who wished to have contralateral surgery for symmetry

\begin{tabular}{|c|c|c|c|c|c|}
\hline \multicolumn{6}{|c|}{ Would you like to have a procedure of the contralateral breast for symmetry? ${ }^{a}$} \\
\hline \multirow{2}{*}{$\begin{array}{l}\text { Satisfaction with aspect of the } \\
\text { operated breast }^{\text {a }}\end{array}$} & \multicolumn{2}{|l|}{ Yes $(n=13)$} & \multicolumn{2}{|c|}{ No $(n=101)$} & \multirow[t]{2}{*}{$p$ value } \\
\hline & Satisfied $^{b}$ & Dissatisfied & Satisfied & Dissatisfied & \\
\hline Appearance of the operated breast & $10(76.9 \%)$ & $3(23.1 \%)$ & $92(91.1 \%)$ & 9 (8.9\%) & 0.139 \\
\hline Size of the operated breast & $8(66.7 \%)$ & $4(33.3 \%)$ & $92(91.1 \%)$ & $9(8.9 \%)$ & $0.032^{*}$ \\
\hline Shape of the operated breast & $8(66.7 \%)$ & $4(33.3 \%)$ & $94(93.1 \%)$ & $7(6.9 \%)$ & $0.017^{*}$ \\
\hline NAC positioning & $10(83.3 \%)$ & $2(16.7 \%)$ & $94(93.1 \%)$ & 7 (6.9\%) & 0.224 \\
\hline NAC appearance & $8(72.7 \%)$ & $3(27.3 \%)$ & $90(89.1 \%)$ & $11(10.9 \%)$ & 0.140 \\
\hline Symmetry & $4(33.3 \%)$ & $8(66.7 \%)$ & $86(85.1 \%)$ & 15 (14.9\%) & $<0.001^{*}$ \\
\hline Appearance of scar & $9(69.2 \%)$ & $4(30.8 \%)$ & $86(86.9 \%)$ & $13(13.1 \%)$ & 0.109 \\
\hline Skin sensitivity & $7(58.3 \%)$ & $5(41.7 \%)$ & $82(82.0 \%)$ & $18(18.0 \%)$ & 0.068 \\
\hline
\end{tabular}

Descriptive statistics of dichotomized answers from the study-specific questionnaire, sub grouped into women who wished to have contralateral surgery compared to those who did not. Presented as count, percentage of sup group in brackets

Fishers exact test was used to find differences between patients who wished to have contralateral surgery for symmetry and those who did not. $p$ value $<0.05$ is considered to represent a significant difference between groups

${ }^{\text {a }}$ No missing values were included

bSatisfied defined as score of "satisfied" or "very satisfied" and dissatisfied defined as a score of "not entirely satisfied" or "dissatisfied" for the aspect of the operated breast evaluated 
Table 7 Correlation between "Satisfaction with breast" and other BREAST-QTM BCT domains

\begin{tabular}{|c|c|c|c|}
\hline & \multicolumn{3}{|c|}{ Other BREAST-Q ${ }^{\text {TM }}$ BCT domains } \\
\hline & Correlation & Interpretation $^{\text {a }}$ & $p$ value \\
\hline 1. Adverse effects of radiation & 0.186 & Very weak & $0.043^{*}$ \\
\hline 2. Psychosocial well-being & 0.562 & Moderate & $<0.001^{*}$ \\
\hline 3. Sexual well-being & 0.584 & Moderate & $<0.001^{*}$ \\
\hline 4. Physical well-being & 0.389 & Weak & $<0.001^{*}$ \\
\hline 5. Satisfaction with information from breast surgeon & 0.441 & Moderate & $<0.001^{*}$ \\
\hline 6. Satisfaction with breast surgeon & 0.214 & Weak & $0.020^{*}$ \\
\hline 7. Satisfaction with medical team & 0.228 & Weak & $0.013^{*}$ \\
\hline 8. Satisfaction with office staff & 0.182 & Very weak & 0.051 \\
\hline
\end{tabular}

Correlation analysis performed using Spearman's correlation assessing rank correlation between BREAST-Q ${ }^{\mathrm{Tm}}$ BCT domain 1 "Satisfaction with breasts" and remaining domains

${ }^{a}$ Spearman's correlation coefficient (rho) measures the strength of the monotonic relationship between paired data and may lie between -1 and $1.0-0.19=$ very weak, $0.2-0.39=$ weak, $0.4-0.59=$ moderate, $0.6-0.79=$ strong, $0.8-1=$ very strong. ${ }^{*} p<0.05$ is considered a statistically significant correlation

O'Connell and Dahlbäck et al. [26, 27]. A slightly higher median $Q$-score was also found in the domain "Psychosocial well-being," and it was also slightly higher or equal in the domain "Sexual well-being" in the current study compared to the other studies. These three domains are considered most likely to be affected by a poor esthetic outcome, supported by the fact that the domains "Psychosocial well-being" and "Sexual well-being" showed the highest rate of correlation with the domain
"Satisfaction with breast" in our study. "Satisfaction with breast" correlated poorly with how participants perceived their contacts with medical care professionals, suggesting that patients are able to dissociate the different aspects of their treatment when responding to the questionnaire. Similar correlation coefficients were found by O'Connell et al. In similarity to both other studies, the domain "Sexual well-being" had a lower response rate than the other domains $[26,27]$. One reason

Table 8 Previous studies evaluating patient satisfaction/QoL with the BREAST-QTM BCT compared to the current study

\begin{tabular}{|c|c|c|c|}
\hline & \multicolumn{3}{|l|}{ First author of study } \\
\hline & Dahlbäck* & O'Connelli* & Current study \\
\hline Year published & 2017 & 2016 & \\
\hline Evaluated surgical method(s) & BCT/WLE & BCT/WLE & OPS \\
\hline Time period when operations were performed & 2008-2012 & 2009-2015 & 2013-2016 \\
\hline Response rate & $71 \%$ & $58 \%$ & $83 \%$ \\
\hline Number of responding participants & 348 & 200 & 120 \\
\hline Radiological tumor extent (mm) & 15 (median value) & 16 (mean value) & 20 (median value) \\
\hline Weight of specimen excised (grams) & - & 32.5 (mean value) & 86 (median value) \\
\hline \multicolumn{4}{|l|}{ Breast $Q^{T M} B C T$ domains } \\
\hline "Satisfaction with breasts" & $66(57-80)^{\mathrm{a}}$ & $68(55-80)$ & $74(59-85)$ \\
\hline "Effects of radiotherapy" & $100(89-100)$ & $89(78.25-100)$ & $100(89-100)$ \\
\hline "Psychosocial well-being" & $82(61-100)$ & $82(63-100)$ & $87(57-100)$ \\
\hline "Sexual well-being" & $60(48-79)$ & $57(45-66)$ & $60(49-69)$ \\
\hline "Physical well-being" & $81(69-92)$ & $75(64-86)$ & $78(69-92)$ \\
\hline "Satisfaction with information from breast surgeon" & $62(53-84)$ & $77(64-100)$ & $75(58-100)$ \\
\hline "Satisfaction with breast surgeon" & $100(81-100)$ & $100(100-100)$ & $100(92-100)$ \\
\hline "Satisfaction with medical team" & $100(92-100)$ & $100(100-100)$ & $100(100-100)$ \\
\hline "Satisfaction with office staff" & $100(93-100)$ & $100(100-100)$ & $100(100-100)$ \\
\hline
\end{tabular}

Summary of the three studies using BREAST- $Q^{\mathrm{TM}} \mathrm{BCT}$ that have presented median or mean values for one or several domains

$B C T$ breast-conserving therapy, OPS oncoplastic surgery, WLE wide local excision

${ }^{a}$ Values are median and interquartile range in brackets

*Dahlback et al. 2017 [26]

**O'Connell et al. 2016 [27] 
might be that many women are no longer sexually active, as they chose not to answer questions regarding "Sexual well-being" by marking "not applicable." A difference between the comparable study cohorts, apart from surgical technique (OPS in the current study compared to different and mixed methods of $\mathrm{BCT}$ ), is that patients in the other two studies were treated during time periods prior to the current study (O'Connell et al. 2009-2015, Dahlbäck et al. 2008-2012). Since the use of OPS has increased during the latest years, perhaps some patients in these other cohorts should have received OPS, if current recommendations had been present then.

In the current study cohort, many previously studied potential risk factors for lower patient satisfaction after BCT did not significantly affect the OR of having a $Q$-score of the BREAST-Q ${ }^{\mathrm{Tm}} \mathrm{BCT}$ domain "Satisfaction with breast" below the median value. Regarding the impact of EPBVE, women that had a resection of $>15 \%$ of the breast were as likely to be satisfied as the women where $<15 \%$ of the breast had been removed. This indicates that a high EPBVE not necessarily impairs the esthetic outcome if techniques of OPS are used and that OPS can thus be beneficial when large resections are necessary. Axillary clearance, neoadjuvant chemotherapy, resected weight > $100 \mathrm{~g}$, and low breast density were associated with lower patient satisfaction in the univariate analysis, and all but specimen weight remained statistically significant when adjusted for age and BMI. However, when tested in a multiple logistic regression model, no independent risk factors were found. One reason for this may be that many of the factors covariate. For example, all but one patient who received neoadjuvant chemotherapy were also operated in the axilla, and patients with low-density breasts tended to have larger breasts, why they were more likely have had resections of $>100 \mathrm{~g}$. It is thereby difficult to differentiate the true impact of the factors studied, since the number of study individuals is too low to make representative subgroups. In a larger study group, significant values would more likely have been found. Further studies evaluating risk factors for lower patient satisfaction and negative effects on HR-QoL after OPS are therefore suggested.

A majority of the women treated with oncoplastic volume displacement techniques did not express a wish for a contralateral procedure for symmetry. This finding supports the approach to offer contralateral surgery in the primary setting only in selected cases, and otherwise as a secondary procedure after individual assessment. Since PRT can cause unpredictable changes to the breast [17, 18], it might be better to wait until the 1-year follow-up visit to see if contralateral surgery is needed.
Achieving a better long-term symmetrical appearance when the "template," in form of the cancer-treated breast, has reached its final outcome could be easier than trying to predict the change over time and compensate for this in the primary setting. Bilateral surgery also demands higher health care costs due to longer operating time and/or more surgeons. In Sweden, as in other countries with a tax-financed healthcare system, the awareness of costs and benefits for healthcare procedures has to be especially high. In addition, effects of contralateral surgery, such as influencing future detection of an eventual later contralateral cancer negatively [38], scars and potential loss of sensation to the areola and increased risk of peri- and postoperative complications [39], must also be taken into consideration.

The strengths of the study include the use of a validated questionnaire, which limits the researcher's imposition. In addition, efforts to remove confounders were made. All patients received PRT, which is a well-known factor that could compromise esthetic outcome. Also, all patients had a contralateral untouched breast, meaning that they could compare the operated breast to an untouched one. This enabled them to be their own controls, to see if the goal of preserving the natural shape and size of the breast was achieved. Another strength in this study was the high response rate. As for most questionnaire-based studies, selection bias cannot be completely ruled out. Perhaps very dissatisfied and very satisfied patients are more prone to respond than patients in the middle of the spectrum, giving more extreme results for the responders compared to the total cohort. Further limitations of the study include the lack of a control group with patients operated with other methods of BCT. The results of this study were therefore compared to groups of women in other studies, with different methods of surgery and postoperative treatment. The current cohort did not include patients operated with volume reduction mammoplasty, i.e., patients selected for this type of oncoplastic procedure were excluded from the material. Since these operations usually are performed bilaterally, perhaps some patients who wanted bilateral surgery from the start were enrolled to volume reduction surgery instead of volume displacement surgery for that reason. In addition, six patients subjected to oncoplastic displacement surgery had been operated with bilateral surgery to achieve symmetry. These patients could not be included in the current study, since the objective was for the patient to compare the operated breast to an untouched one. With only six patients, it would have been difficult to draw any reliable conclusions, why no further analyses were attempted for this group in this material. However, this poses a risk of selection bias in the current cohort, since these patients in fact were not satisfied with unilateral 
surgery. Also, due to the retrospective design of this study, only the postoperative BREAST- $\mathrm{Q}^{\mathrm{m}}$ BCT module was used. Since the BREAST- $Q^{\text {ps }}$ BCT has a preoperative module, it would have been valuable to create a baseline measurement, to illustrate the change of well-being pre- and postoperatively. Especially in the psychosocial and sexual domains, in which a change in the patients view of herself, psychological health or sexuality are aspects of interest.

In this study, the patients' level of satisfaction and aspects of HR-QoL were the primary end-points. As these results are subjective, it could be valuable to evaluate the esthetic result also by more objective evaluation modalities, such as software-based methods (for example BCCT.core $[40,41])$, in future studies.

\section{Conclusion}

In this study cohort of breast cancer patients, treated unilaterally with oncoplastic volume displacement surgery and with an untouched contralateral breast, the median Q-score of the BREAST-Q" domain "Satisfaction with breast" was slightly higher than those presented in other previously published studies evaluating BCS with BREAST- $\mathrm{Q}^{\mathrm{TN}}$, despite larger resections. The results indicate that oncoplastic volume displacement techniques can be beneficial in the surgical treatment of breast cancer for selected patients. In this study, no independent risk factor for lower patient satisfaction was identified. Larger study cohorts are needed to further investigate potential risk factors for lower patient satisfaction after oncoplastic surgery. Most patients in the current study were not interested in a contralateral procedure. In patients treated with oncoplastic volume displacement surgery, contralateral surgery for symmetry is suggested to be performed only after individual evaluation and as a delayed procedure.

\section{Abbreviations \\ BCS: Breast-conserving surgery; BCT: Breast-conserving therapy; BMI: Body mass index; Cl: Confidence interval; EPBVE: Estimated percentage of breast volume excised; HR-QoL: Health-related quality of life; IQR: Interquartile range; NAC: Nipple-areolar complex; NCSP: NOMESCO classification of surgical procedures; OPS: Oncoplastic breast-conserving surgery; OR: Odds ratio; PROM: Patient-reported outcome measure; PRT: Postoperative radiotherapy; WLE: Wide local excision}

\section{Acknowledgements}

The authors would like to thank Professor Jonas Manjer for the valuable help with statistical methods and input on the manuscript and Dr. Rogvi Wintherheig Rasmussen for the guidance in how to measure volume and for evaluating the breast density from mammography images.

BREAST-Q ${ }^{T M}$ copyright notice: Memorial Sloan Kettering Cancer Center and the University of British Columbia, 2006, all rights reserved. Contact information and permission to use:

MAPI Research Trust, Lyon, France (qportfolio.org; qportfolioteam@gmail.com).

\section{Authors' contributions}

All authors have made substantial contributions. AG has been involved in the acquisition, analysis, and interpretation of the patient data. CD has contributed by providing the template for the additional questionnaire, analysis, and interpretation of the data. KÅ has contributed as the main supervisor of AG, conception and design of the study, and with acquisition and interpretation of the data. All have revised the manuscript critically for important intellectual content, and all have given the final approval of the version to be published.

\section{Funding}

Not applicable. No funding was received for this study

\section{Availability of data and materials}

The datasets generated and/or analyzed during the current study are not publicly available due to the integrity of the individual participants in the study but are available from the corresponding author on reasonable request.

Ethics approval and consent to participate

The Ethics Committee of Lund University approved the study (DNR 2018/50). Informed written consent was retrieved from all individual participants included in the study.

\section{Consent for publication}

Not applicable

\section{Competing interests}

The authors declare that they have no competing interests.

\section{Author details}

${ }^{1}$ Department of Surgery, Region Blekinge Hospital, Karlskrona, Sweden. ${ }^{2}$ Department of Clinical Sciences Lund, Surgery, Skåne University Hospital, Lund University, Lund, Sweden.

Received: 24 February 2019 Accepted: 27 May 2019

Published online: 05 June 2019

\section{References}

1. Annual report from the national breast cancer registry 2015 [Swedish] Regional cancer centres in collaboration. https://www.cancercentrum.se/ globalassets/cancerdiagnoser/brost/kvalitetsregister/nationell_brostcancer rapport_2015-2pdf.pdf]. Accessed 14 Jan 2019.

2. Fisher B, Anderson S, Bryant J, Margolese RG, Deutsch M, Fisher ER, et al. Twenty-year follow-up of a randomized trial comparing total mastectomy, lumpectomy, and lumpectomy plus irradiation for the treatment of invasive breast cancer. N Engl J Med. 2002;347(16):1233-41.

3. Litiere S, Werutsky G, Fentiman IS, Rutgers E, Christiaens MR, Van Limbergen $E$, et al. Breast conserving therapy versus mastectomy for stage I-II breast cancer: 20 year follow-up of the EORTC 10801 phase 3 randomised trial. Lancet Oncol. 2012;13(4):412-9.

4. Schover LR. The impact of breast cancer on sexuality, body image, and intimate relationships. CA Cancer J Clin. 1991:41(2):112-20.

5. Al-Ghazal SK, Fallowfield L, Blamey RW. Does cosmetic outcome from treatment of primary breast cancer influence psychosocial morbidity? Eur J Surg Oncol. 1999;25(6):571-3.

6. Clough KB, Cuminet J, Fitoussi A, Nos C, Mosseri V. Cosmetic sequelae after conservative treatment for breast cancer: classification and results of surgical correction. Ann Plast Surg. 1998:41(5):471-81.

7. Bulstrode NW, Shrotria S. Prediction of cosmetic outcome following conservative breast surgery using breast volume measurements. Breast. 2001;10(2):124-6.

8. Chan SW, Cheung PS, Lam SH. Cosmetic outcome and percentage of breast volume excision in oncoplastic breast conserving surgery. World J Surg. 2010;34(7):1447-52.

9. Cochrane RA, Valasiadou P, Wilson AR, Al-Ghazal SK, Macmillan RD. Cosmesis and satisfaction after breast-conserving surgery correlates with the percentage of breast volume excised. Br J Surg. 2003;90(12):1505-9.

10. Al-Ghazal SK, Blamey RW, Stewart J, Morgan AA. The cosmetic outcome in early breast cancer treated with breast conservation. Eur J Surg Oncol. 1999; 25(6):566-70.

11. Vrieling C, Collette L, Fourquet A, Hoogenraad WJ, Horiot JH, Jager JJ, et al. The influence of patient, tumor and treatment factors on the cosmetic results after breast-conserving therapy in the EORTC 'boost vs. no boost' trial. EORTC Radiotherapy and Breast Cancer Cooperative Groups. Radiother Oncol 2000;55(3):219-232. 
12. Dahlback C, Manjer J, Rehn M, Ringberg A. Determinants for patient satisfaction regarding aesthetic outcome and skin sensitivity after breastconserving surgery. World J Surg Oncol. 2016;14(1):303.

13. Clough KB, Kaufman GJ, Nos C, Buccimazza I, Sarfati IM. Improving breast cancer surgery: a classification and quadrant per quadrant atlas for oncoplastic surgery. Ann Surg Oncol. 2010;17(5):1375-91.

14. Waljee JF, Hu ES, Newman LA, Alderman AK. Predictors of breast asymmetry after breast-conserving operation for breast cancer. J Am Coll Surg. 2008; 206(2):274-80

15. Ozmen T, Polat AV, Polat AK, Bonaventura M, Johnson R, Soran A. Factors affecting cosmesis after breast conserving surgery without oncoplastic techniques in an experienced comprehensive breast center. Surgeon. 2015; 13(3):139-44.

16. Yi A, Kim HH, Shin HJ, Huh MO, Ahn SD, Seo BK. Radiation-induced complications after breast cancer radiation therapy: a pictorial review of multimodality imaging findings. Korean J Radiol. 2009;10(5):496-507.

17. White J, Achuthan R, Turton P, Lansdown M. Breast conservation surgery: state of the art. Int J Breast Cancer. 2011;2011:107981.

18. Agrawal A. Oncoplastic breast surgery and radiotherapy-adverse aesthetic outcomes, proposed classification of aesthetic components, and causality attribution. Breast J. 2019:25(2):207-18.

19. Dahlback C, Manjer J, Rehn M, Ringberg A. Patients undergoing breastconserving surgery can benefit from the opportunity to participate in choosing their surgical technique. World J Surg. 2017;41(3):734-41.

20. Franceschini G, Terribile D, Magno S, Fabbri C, Accetta C, Di Leone A, et al. Update on oncoplastic breast surgery. Eur Rev Med Pharmacol Sci. 2012; 16(11):1530-40.

21. Santos G, Urban C, Edelweiss MI, Zucca-Matthes G, de Oliveira VM, Arana GH, et al. Long-term comparison of aesthetical outcomes after oncoplastic surgery and lumpectomy in breast cancer patients. Ann Surg Oncol. 2015;22(8):2500-8.

22. Smeele HP, der Does de Willebois EML V, Eltahir Y, De Bock GH, Van Aalst VC, Jansen L. Acceptance of contralateral reduction mammoplasty after oncoplastic breast conserving surgery: a semi-structured qualitative interview study. Breast. 2019:45:97-103.

23. Pusic AL, Klassen AF, Scott AM, Klok JA, Cordeiro PG, Cano SJ. Development of a new patient-reported outcome measure for breast surgery: the BREASTQ. Plast Reconstr Surg. 2009;124(2):345-53.

24. Liu LQ, Branford OA, Mehigan S. BREAST-O measurement of the patient perspective in oncoplastic breast surgery: a systematic review. Plast Reconstr Surg Glob Open. 2018;6(8):e1904

25. Chand ND, Browne V, Paramanathan N, Peiris LJ, Laws SA, Rainsbury RM. Patient-reported outcomes are better after oncoplastic breast conservation than after mastectomy and autologous reconstruction. Plast Reconstr Surg Glob Open. 2017;5(7):e1419.

26. Dahlback C, Ullmark JH, Rehn M, Ringberg A, Manjer J. Aesthetic result after breast-conserving therapy is associated with quality of life several years after treatment. Swedish women evaluated with BCCT.core and BREAST-Q. Breast Cancer Res Treat. 2017;164(3):679-87.

27. O'Connell RL, DiMicco R, Khabra K, O'Flynn EA, deSouza N, Roche N, et al. Initial experience of the BREAST-Q breast-conserving therapy module. Breast Cancer Res Treat. 2016;160(1):79-89.

28. Atisha DM, Rushing CN, Samsa GP, Locklear TD, Cox CE, Shelley Hwang E, et al. A national snapshot of satisfaction with breast cancer procedures. Ann Surg Oncol. 2015;22(2):361-9.

29. van Paridon MW, Kamali P, Paul MA, Wu W, Ibrahim AMS, Kansal KJ, et al. Oncoplastic breast surgery: achieving oncological and aesthetic outcomes. J Surg Oncol. 2017;116(2):195-202.

30. Nordic medico-statistical committee (NOMESCO). NOMESCO classification of surgical procedures. Copenhagen: NOMESCO; 2010.

31. Panhofer P, Ferenc V, Schutz M, Gleiss A, Dubsky P, Jakesz R, et al. Standardization of morbidity assessment in breast cancer surgery using the Clavien Dindo classification. Int J Surg. 2014;12(4):334-9.

32. Kalbhen CL, McGill JJ, Fendley PM, Corrigan KW, Angelats J. Mammographic determination of breast volume: comparing different methods. AJR Am J Roentgenol. 1999;173(6):1643-9.

33. Kayar R, Civelek S, Cobanoglu M, Gungor O, Catal H, Emiroglu M. Five methods of breast volume measurement: a comparative study of measurements of specimen volume in 30 mastectomy cases. Breast Cancer (Auckl). 2011;5:43-52

34. American College of Radiology. ACR BI-RADS Atlas. 5th ed. Reston: American College of Radiology; 2013.
35. Sentinel Node Biopsy in Breast Cancer: Omission of Axillary Clearance After Micrometastasis. Available from: https://ClinicalTrials.gov/show/ NCT02049632. Accessed 14 Jan 2019.

36. Sentinel Node Biopsy in Breast Cancer: Omission of Axillary Clearance After Macrometastases. A Randomized Trial [Available from: https://ClinicalTrials. gov/show/NCT02240472]. Accessed 14 Jan 2019.

37. Socialstyrelsen. National guidelines for breast, prostate and colon cancer treatment [Swedish]. Updated version (2015); 2014. p. 24-38.

38. Kim H, Kang BJ, Kim SH, Kim HS, Cha ES. What we should know in mammography after reduction mammoplasty and mastopexy? Breast Cancer. 2015;22(4):391-8

39. McCulley SJ, Durani P, Macmillan RD. Therapeutic mammaplasty for centrally located breast tumors. Plast Reconstr Surg. 2006;117(2):366-73.

40. Cardoso MJ, Cardoso J, Amaral N, Azevedo I, Barreau L, Bernardo M, et al. Turning subjective into objective: the BCCT.core software for evaluation of cosmetic results in breast cancer conservative treatment. Breast. 2007;16(5): 456-61.

41. Cardoso MJ, Cardoso JS, Oliveira HP, Gouveia P. The breast cancer conservative treatment. Cosmetic results - BCCT.core - Software for objective assessment of esthetic outcome in breast cancer conservative treatment: a narrative review. Comput Methods Prog Biomed. 2016;126:154-9.

\section{Publisher's Note}

Springer Nature remains neutral with regard to jurisdictional claims in published maps and institutional affiliations.
Ready to submit your research? Choose BMC and benefit from:

- fast, convenient online submission

- thorough peer review by experienced researchers in your field

- rapid publication on acceptance

- support for research data, including large and complex data types

- gold Open Access which fosters wider collaboration and increased citations

- maximum visibility for your research: over $100 \mathrm{M}$ website views per year

At $\mathrm{BMC}$, research is always in progress.

Learn more biomedcentral.com/submissions 